
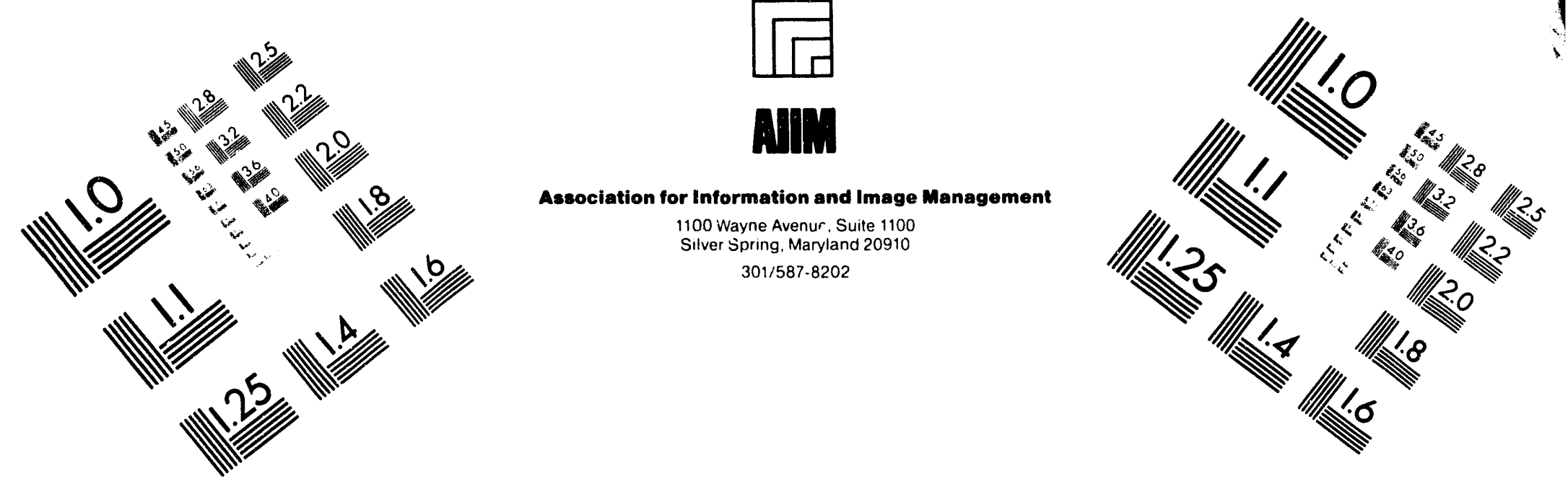

\title{
Centimeter
}

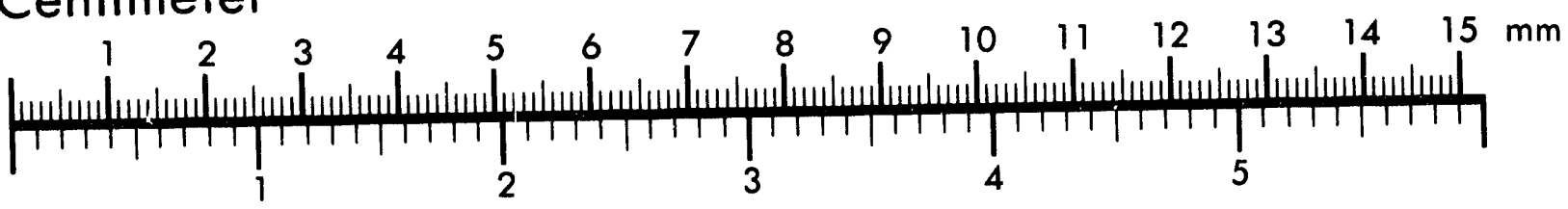
Inches
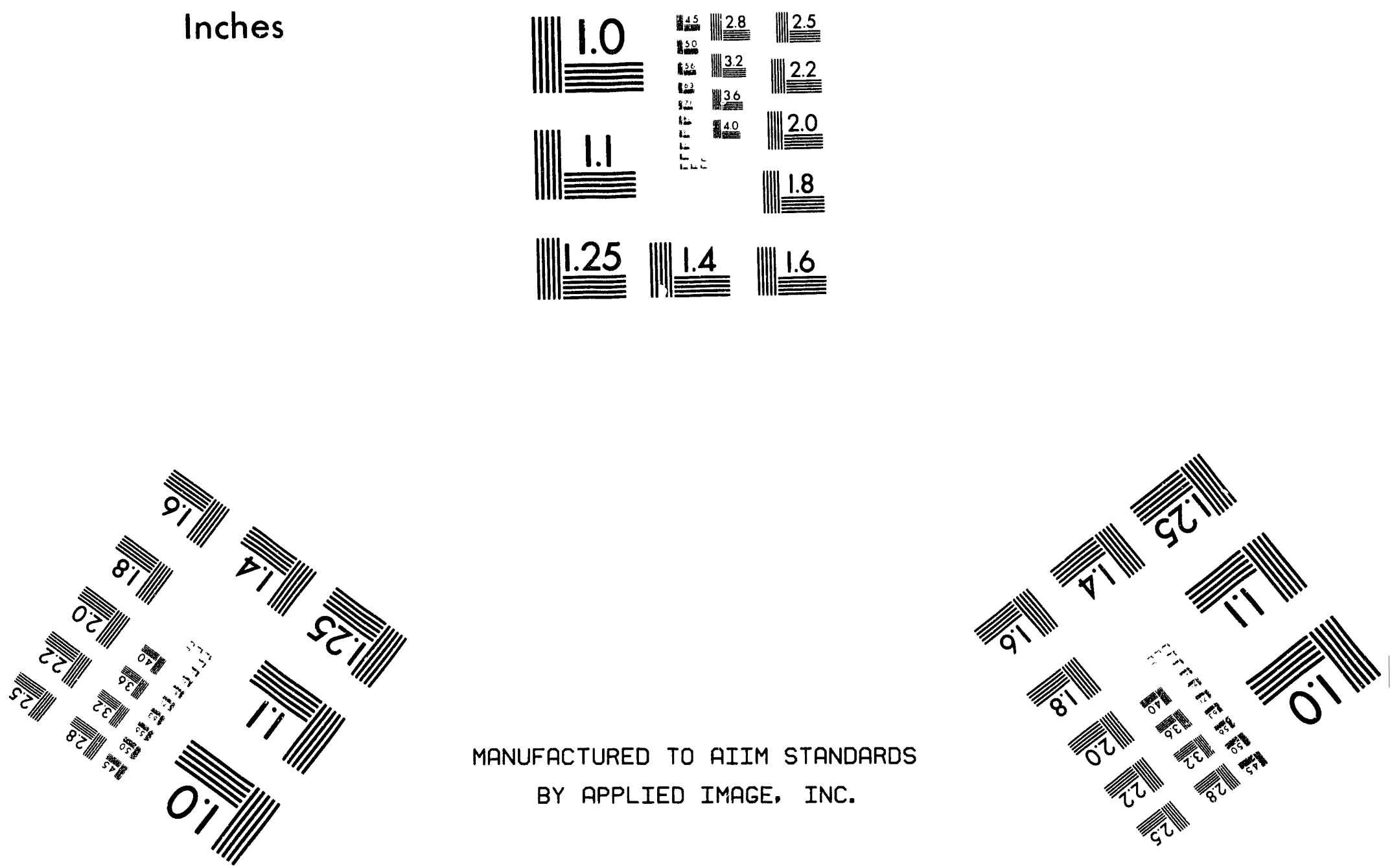

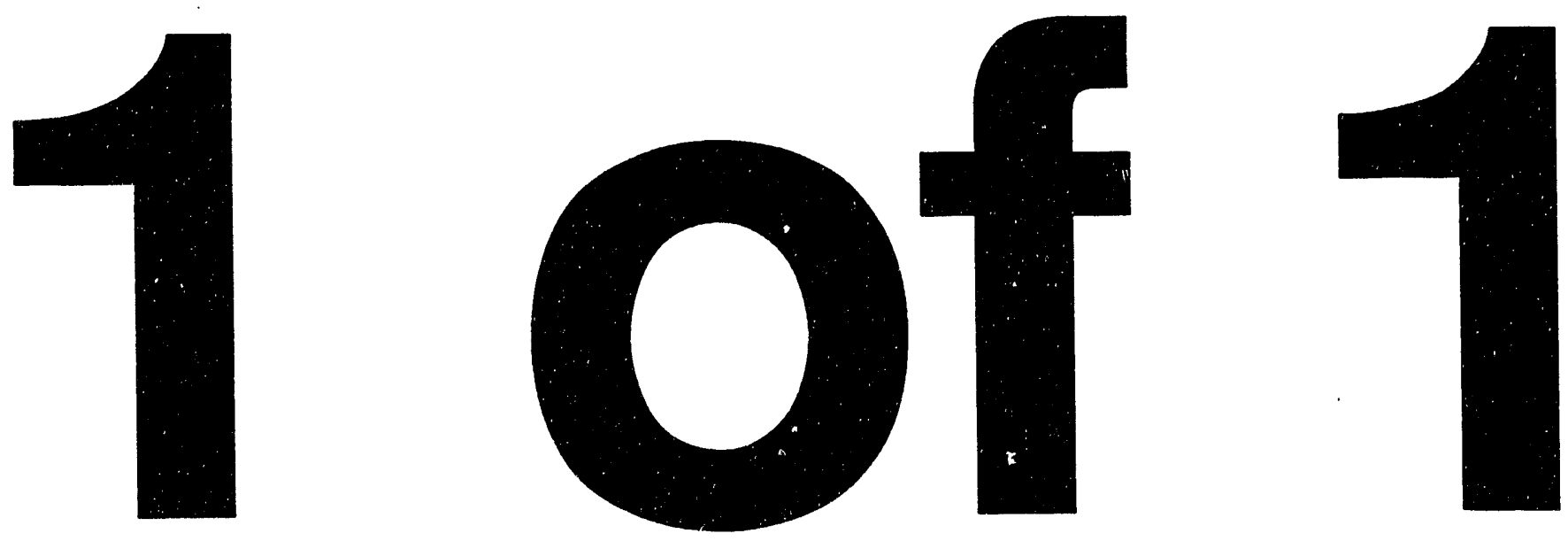

$\therefore$ 
SUMMARY REPORT ON DE-FGO2-90ER14143

Determination of Sulvation Kinetics in Supercritical Fluids

Professor Frank V. Bright

\author{
Department of Chemistry \\ Acheson Hall \\ State University of New York at Buffalo \\ Buffalo, NY 14214 \\ (716) 829-3615 (office) \\ (716) 829-2960 (FAX) \\ CHEFVB@UBVMS (e-mail)
}

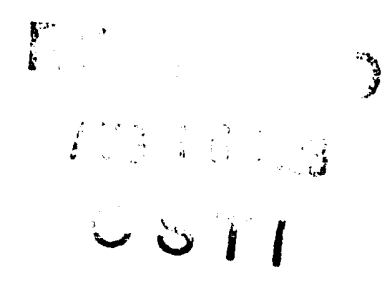

Prepared January 1993

1

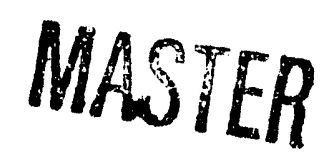


The PI has received DOE support since August 1990 (DE-FGO2-90ER14143) for a project entitled "Determination of Solvation Kinetics in Supercritical Fluids". The aim of this work was to improve our understanding of solvation processes in pure and entrainer-modified supercritical fluids. Specific topics addressed were the: (1) kinetics for solvation in supercritical media; (2) influence of entrainers on solvation; (3) reversibility of the solvation process (i.e., can equilibrium information be recovered); (4) effects of solvation on intramolecular solutesolute interaction kinetics; and (5) impact of fluid density on these processes. Because of its inherent sensitivity, selectivity, and time resolution, we used time-resolved fluorescence spectroscopy as our main analytical tool. The results from this project provided new insight into the kinetics and mechanisms of solute-fluid, solute-entrainer, and solute-solute interactions in supercritical media. In turn, this information has lead to a more accurate molecular understanding of solvation processes in supercritical fluids.

During the previous 2.5 years we have (in brief):

- been the first group to use sophisticated time-resolved fluorescence techniques ${ }^{2}$ to probe dynamical processes in supercritical solvents. 1,3

- showin that organized macromolecular assemblies can serve as good models for studying solvation processes in supercritical solvents. $6,7,9-11,16$

- demonstrated that solute-fluid interactions proceed reversibly, and over a broad time scale (subpicosecond to nanoseconds). $4,5,15$

- developed a new method for determining directly the average size of a solute-fluid cluster in supercritical solvents. 21

- shown that solute-fluid clusters are made-up of an ensemble of species with varying 
physicochemical properties. ${ }^{12,13}$

: determined the detailed kinetics of intramolecular solute-solute (pyrene-pyrene excimer) interactions in supercritical solvents. ${ }^{14,18,20,23}$

- elucidated the effects of continuous phase density and temperature on the mechanistics of pyrene excimer formation (solute-solute interactions) in $\mathrm{CO}_{2}, \mathrm{C}_{2} \mathrm{H}_{4}, \mathrm{CF}_{3} \mathrm{H}$, and entrainer modified $\mathrm{CO}_{2} \cdot 14,15,18,20,23$

- reported the first clear evidence for solvent (water) reorganization within reverse micelles maintained in liquid heptane. 8

- extended the above work and showed how the continuous phase (ethane and propane) density could be used to control the partitioning of solutes into and out of a reverse micelle. ${ }^{19,22}$

- reported that one can control the internal dynamics of a water-swollen reverse micelle maintained in a highly compressible fluid (e.g., propane). ${ }^{22}$

- developed a new fiber-optic-based interface for carrying-out spectroscopic measurements in supercritical solvents. 24

- been the first to probe the in-situ conformation of biomolecules maintained in supercritical solvents. ${ }^{17}$

On the following pages we list publications, presentations, and Ph.D. graduates resulting (in whole or in part) from the previous DOE award. In summary, 24 publications have appeared or are in press, 44 presentations have or will be delivered (19 invited), and 6 Ph.D. degrees have been awarded during the previous 2.5 years of DOE support. 


\section{RESEARCH PUBLICATIONS}

1) F.V. Bright" and M.E.P. McNally": "Supercritical Fluid Technology: Theoretical and Applied Approaches to Analytical Chemistry", (1992) ACS Symposium Series, Vol. 488.

2) F.V. Bright", T.A. Betts and K.S. Litwiler: "Advances in Multifrequency Phase and Modulation Fluorimetric Analysis" C.R.C. Crit. Rev. Anal. Chem. (1990), 21, 389405.

3) M.E. McNally" and F.V. Bright": "Fundamental Studies and Applications of Supercritical Fluids: A Review" in Supercritical Fluid Technology: Theoretical and Applied Approaches to Analytical Chemistry, F.V. Bright and M.E.P. McNally, Eds. (1992) ACS Symposium Series, Vol. 488, Chapter 1.

4) T.A. Betts and F.V. Bright": "Instrumentation for Steady-State and Dynamic Fluorescence and Absorbance Studies in Supercritical Media" Appl. Spectrosc. (1990), 44, 1196-1202.

5) T.A. Betts and F.V. Bright": "Reversible Excited-State Transient Solvation in Binary Supercritical Fluids Revealed by Multifrequency Phase and Modulation Fluorescence" Appl. Spectrosc. (1990), 44, 1203-1209.

6) J. Huang and F.V. Bright : "Unimodal Lorentzian Lifetime Distribution of the 2,6Anilinonaphthalene-Beta-Cyclodextrin Inclusion Complex Recovered by Multifrequency Phase-Modulation Fluorometry" J. Phys. Chem. (1990), 94, 8457-8463.

7) G.C. Catena and F.V. Bright : "Continuous Lifetime Distributions of Beta-Cyclodextrin - Anilinonaphthalene Sulfonic Acid Inclusion Complexes" J. Fluorescence (1991), 1, 3139.

8) J. Zhang and F.V. Bright": "Nanosecond Reorganization of Water Within the Interior of Reversed Micelles Revealed by Frequency-Domain Fluorescence Spectroscopy" J. Phys. Chem., (1991), 25, 7900-7907.

9) K.S. Litwiler and F.V. Bright": "Investigation of Beta-Cyclodextrin Immobilized at Silica Surfaces by Fluorescence Spectroscopy" Appl. Spectrosc., (1992), 46, 169-175.

10) J. Huang and F.V. Bright": "Microheterogeneity of Sodium Dodecylsulfate Micelles Probes by Frequency-Domain Fluorometry" Appl. Spectrosc., (199\%), 46, 329-339.

11) J. Huang, G.C. Catena and F.V. Bright": "Fluorescence-Based Investigations of Effects of Alcohol Co-Solvents on the Nature of Cyclodextrin Inclusion Complexation" Appl. Spectrosc., (1992), 46, 606-614. 
12) T.A. Betts, J. Zagrobelny and F.V. Bright": "Investigation of Solute-Fluid Interactions in Supercritical $\mathrm{CF}_{3} \mathrm{H}$ : A Multifrequency Phase and Modulation Fluorescence Study J. Supercrit. Fluids, (1992), 5, 48-54.

13) T.A. Betts, J. Zagrobelny and F.V. Bright": "Elucidation of Solute-Fluid Interactions in Supercritical $\mathrm{CF}_{3} \mathrm{H}$ by Steady-State and Time-Resolved Fluorescence Spectroscopy" in, Supercritical Fluid Technology: Theoretical and Applied Approaches to Analytical Chemistry F.V. Bright and M.E.P. McNally, Eds. (1992) ACS Symposium Series, Vol. 488, Chapter 4.

14) J. Zagrobelny and F.V. Bright : "Investigation of Pyrene Excimer Formation in Supercritical $\mathrm{CO}_{2}$ " in Supercritical Fluid Technology: Theoretical and Applied Approaches to Analytical Chemistry, F.V. Bright and M.E.P. McNally, Eds. (1992) ACS Symposium Series, Vol. 488, Chapter 6.

15) T.A. Betts and F.V. Bright": "Investigation of Solute-Cosolvent Interactions in Supercritical Media: A Frequency-Domain Fluorescence Study" in Supercritical Fluid Technology: Theoretical and Applied Approaches to Analytical Chemistry, F.V. Bright and M.E.P. McNally, Eds. (1992) ACS Symposium Series, Vol. 488, Chapter 8.

16) F.V. Bright", G.C. Catena, J. Huang, J: Zagrobelny and J. Zhang: "Dynamic Fluorescence Investigations in Beta-Cyclodextrin Orga\%ized Media" Advances in Multidimensional Luminescence, Vol. 2, I.M. Warner and L.B. McGown, Eds., JAI Press, in press (1992).

17) J. Zagrobelny and F.V. Bright": "In-Situ Studies of Protein Conformation in Supercritical Fluids: Trypsin in Carbon Dioxide" Biotechnol. Prog. (1992), , 421-423.

18) J. Zagrobelny, T.A. Betts and F.V. Bright": "Steady-State and Time-Resolved Fluorescence Investigations of Pyrene Excimer Formation in Supercritical $\mathrm{CO}_{2}$ " J. Am. Chem. Soc. (1992), 114, 5249-5257.

19) J. Zhang and F.V. Bright": "Steady-State and Time-Resolved Fluorescence Studies of Bis(2-ethylhexyl) Sodium Succinate (AOT) Reverse Micelles in Supercritical Ethane" J. Phys. Chem. (1992), 26, 5633-5641.

20) J. Zagrobelny and F.V. Bright": "Influence of Solute-Fluid Clustering on the Photophysics of Pyrene Emission in Supercritical $\mathrm{C}_{2} \mathrm{H}_{4}$ and $\mathrm{CF}_{3} \mathrm{H}$ " J. Am. Chem. Soc. (1992), 114, 7821-7826.

21) T.A. Betts, J. Zagrobelny and F.V. Bright": "Spectroscopic Determination of SoluteFluid Cluster Size in Supercritical $\mathrm{N}_{2} \mathrm{O}^{\prime \prime}$ J. Am. Chem. Soc. (1992), 114, 8163-8171.

22) J. Zhang and F.V. Bright ${ }^{*}$ : "Probing the Internal Dynamics of Reverse Micelles Formed 
in Highly Compressible Solvents: Aerosol-OT in Nearcritical Propane" J. Phys. Chem. (1992), 96, 9068-9073.

23) J. Zagrobelny and F.V. Bright": "Probing Solute-Entrainer Interactions in MatrixModified Supercritical $\mathrm{CO}_{2} "$ J. Am. Chem. Soc., in press (1993).

24) J. Zagrobelny, M. Li, R. Wang, T.A. Betts and F.V. Bright": "Simple Fiber-OpticBased Interface to Facilitate Spectroscopic Measurements in Supercritical Solvents" Appl. Spectrosc., in press (1993).

\section{PRESENTATIONS}

\section{Contributed:}

1) T.A. Betts and F.V. Bright": "Kinetics of Solvation in Supercritical Fluids by Frequency-Domain Fluorescence Spectroscopy" presented: $17^{\text {th }}$ FACSS Conference, Cleveland, OH (Oct. '90).

2) G.C. Catena and F.V. Bright ${ }^{*}$ : "Fluorescence Lifetime Studies of BetaCyclodextrin/Anilino Naphthyl Sulfonate Inclusion Complexes" presented: $17^{\text {th }}$ FACSS Conference, Cleveland, OH (Oct. '90).

3) L. Zagrobelny, T.A. Betts and F.V. Bright": "Time-Resolved Fluorescence Investigations of Pyrene Excimer Formation in Supercritical Fluid" presented: $17^{\text {th }}$ FACSS Conference, Cleveland, OH (Oct. '90).

4) L. Huang and F.V. Bright" : "Nanosecond Kinetic; of Anilino Naphthalene Sulfonates in Micelles Recovered by Multifrequency Phase-Modulation Fluorescence Spectroscopy" presented: $17^{\text {th }}$ FACSS Conference, Cleveland, OH (Oct. '90).

ذ) E.V. Bright", T.A. Betts and J. Zagrobelny: "Investigation of Supercritical Fluid Solvation Kinetics and Mechanisms Using Time-Resolved Fluorescence Spectroscopy" presented: $2^{\text {nd }}$ International Conference on Supercritical Fluids, Boston, MA (May '91).

6) T.A. Betts and F.V. Bright": "Kinetics of Solvation in Supercritical Fluids Using Frequency-Domain Fluorescence" presented: Chicago, IL, $42^{\text {nd }}$ Pittsburgh Conference (Mar. '91).

7) K.S. Litwiler and F.V. Bright : "Dynamic Fluorescence Studies of Anilino-Naphthalene Sulfonates Complexed to Surface-Immobilized Beta-Cyclodextrin" presented: Chicago, IL, $42^{\text {nd }}$ Pittsburgh Conference (Mar. '91).

8) L. Huang and F.V. Bright": "Investigation of Organized Media by Frequency-Domain Fluorumetry" prescitted: Chicago, IL, $42^{\text {nd }}$ Pittsburgh Conference (Mar. '91). 
9) G.C. Catena and F.V. Bright ${ }^{*}$ : "Investigation of Alcohol Co-Solvents on the Dynamical Properties of Cyclodextrin Inclusion Complexes" presented: Chicago, IL, $42^{\text {nd }}$ Pittsburgh Conference (Mar. '91).

10) T.A. Betts and F.V. Bright : "Investigation of Solvation Kinetics in Supercritical Fluidis" presented: $9^{\text {th }}$ Student Symposium, SUNY-Buffalo, Buffalo, NY (May '91).

11) L. Zagrobelny and F.V. Bright": "Fluorescence Investigation of Pyrene Excimer Formation in Supercritical $\mathrm{CO}_{2}$ " presented: $9^{\text {th }}$ Student Symposium, SUNY-Buffalo, Buffalo, NY (May '91).

12) L.Huang, G.C. Catena and F.V. Bright " : "Fluorescence Investigations of the Effects of Alcohol-Co-Solvents on the Nature of Cyclodextrin Inclusion Complexation" presented: $9^{\text {th }}$ Student Symposium, SUNY-Buffalo, Buffalo, NY (May '91).

13) J. Zhang and F.V. Bright": "Water Reorganization within the Interior of AOT Reverse Micelles Revealed by Frequency-Domain Fluorescence Spectroscopy" presented: $9^{\text {th }}$ Student Symposium, SUNY-Buffalo, Buffalo, NY (May '91).

14) T.A. Betts and F.V. Bright": "Studies of Solute-Solvent Interactions in Supercritical Fluids by Fluorescence Polarization" presented: $43^{\text {rd }}$ Pittsburgh Conference, New Orleans, LA (Mar. '92).

15) J. Zagrobelny and F.V. Bright : "Fluorescence Investigation of Excited-State Reactions in Supercritical Fluids" presented: $43^{\text {rd }}$ Pittsburgh Conference, New Orleans, LA (Mar. '92).

16) L. Zagrobelny and F.V. Bright ": "Studies of Protein Conformation in Supercritical $\mathrm{CO}_{2}$ " presented: $43^{\text {rd }}$ Pittsburgh Conference, New Orleans, LA (Mar. '92).

17) L. Zhang and F.V. Bright : "Reverse Micelles in Supercritical Fluids: A Steady-State and Time-Resolved Fluorescence Study" presented: $43^{\text {rd }}$ Pittsburgh Conference, New Orleans, LA (Mar. '92).

18) L. Zagrobelny and F.V. Bright : "Fluorescence Investigation of Excited-State Reactions in Supercrtical Fluids" presented: $10^{\text {th }}$ Student Symposium, SUNY-Buffalo, Buffalo, NY (May '92).

19) L. Zhang and F.V. Bright ": "Pressure-Dependent Excited-State Solvent relaxation of 1,8ANS within AOT Reverse Micelles" presented: $10^{\text {th }}$ Student Symposium, SUNY-Buffalo, Buffalo, NY (May '92).

20) L. Zhang and F.V. Bright": "Pressure-Dependent Solvent Relaxation Within Reverse Micelles Formed in Supercritical Fluids" presented: $19^{\text {th }}$ FACSS Conference, 
Philadelphia, PA (Sept. '92).

21) L.K. Rice, T.A. Betts and F.V.Bright": "Probing the Local Solute Environment in Supercritical Fluids" presented: $19^{\text {th }}$ FACSS Conference, Philadelphia, PA (Sept. '92).

22) L. Zagrobelny and F.V. Bright": "Enzyme Behavior in Microaqueous Environments Under Supercritical Conditions" presented: $19^{\text {th }}$ FACSS Conference, Philadelphia, PA (Sept. '92).

23) W.R. Peifer, J.K. Rice, J. Zagrobelny and F.V. Bright": "The Chemistry of Tethered Bis-Pyrenes in Supercritical Solvents" to be presented: $44^{\text {th }}$ Pittsburgh Conference, Atlanta, GA (Mar. '93).

24) L.K. Rice and F.V. Bright": "Probing Solute-Fluid Clustering in Supercritical Fluids" to be presented: $44^{\text {th }}$ Pittsburgh Conference, Atlanta, GA (Mar. '93).

25) R.A. Dunbar and F.V. Bright ": "Comparison of Inter- and Intramolecular Cyclodextrin Complexes" to be presented: $44^{\text {th }}$ Pittsburgh Conference, Atlanta, GA (Mar. '93).

\section{Invited:}

1) "Uncovering Solvation Processes in Supercritical Fluids with Picosecond Fluorescence Spectroscopy" presented: Buffalo State College, Buffalo, NY (Dec. '91).

2) "In-Situ Studies of Supercritical Fluids" presented: University of Pittsburgh, Pittsburgh, PA (Jan. '92).

3) "In-Situ Studies of Supercritical Fluids" presented: Pennsylvania State University, University Park, PA (Feb. '92).

4) "Probing the Dynamics of Supercritical Fluids by Time-Resolved Spectroscopy" presented: Louisiana State University, Baton Rouge, LA (March '92).

5) "Studying Solvation Processes in Supercritical Fluids with Picosecond Fluorescence Spectroscopy" presented: University of Waterloo, Waterloo, Ontario (March '92).

6) "Studying the Unique Chemistry of Supercritical Fluids by Time-Resolved Fluorescence Spectroscopy" to be presented: University of Ottawa, Ottawa, Ontario (Jan. '93).

7) "Probing the Chemistry in Supercrtical Fluids with Time-Resolved Fluorescence Spectroscopy" to be presented: University of Missouri, Columbia, MO (Feb. '93).

8) E.V. Bright ${ }^{*}$, R.E. Bashnagel, T.A. Betts, G.C. Catena, J. Huang, P.M. Kluczynski, 
K.S. Litwiler, Z. Qian, J. Zagrobelny and J. Zhang: "Recent Analytical Applications of Dynamic Fluorescence Spectroscopy" presented: Gordon Research Conference on Analytical Chemistry, New Hampton, NH (Aug. '90).

9) F.V.Bright ${ }^{*}$, T.A. Betts and J. Zagrobelny: "Investigation Solvation Processes in Polar Supercritical Fluids" presented: $201^{\text {st }}$ ACS National Meeting, Atlanta, GA (Apr. '91).

10) T.A. Betts and F.V. Bright": "Transient Solvation in Supercritical Fluids" presented: $201^{\text {st }}$ ACS National Meeting, Atlanta, GA (Apr. '91).

11) L. Zagrobelny and F.V. Bright": "Fluorescence Inve tigations of Pyrene Excimer Formation in Supercritical $\mathrm{CO}_{2}{ }^{\prime \prime}$ presented: $201^{\text {st }}$ ACS National Meeting, Atlanta, GA (Apr. '91).

12) G.C. Catena, J. Huang, K.S. Litwiler, J. Zhang and F.V.Bright" : "Impact of Continuous Lifetime Distributions in Organized Media" presented: $201^{\text {st }}$ ACS National Meeting, Atlanta, GA (Apr. '91).

13) T.A. Betts, J. Zagrobelny and F.V. Bright": "Kinetics and Mechanisms of Supercritical Fluid Solvation Revealed by Time-Resolved Fluorescence Spectroscopy" presented: III ${ }^{\text {rd }}$ International Symposium on Supercritical Fluid Chromatography, Park City, UT (Jan. '91).

14) T.A. Betts, J. Zagrobelny and F.V. Bright": "Uncovering Solvation Processes in Supercritical Fluids with Picosecond Fluorescence Spectroscopy" presented: $30^{\text {th }}$ Eastern Analytical Symposium, Somerset, NJ (Nov. '91).

15) T.A. Betts, J. Zagrobelny, J. Zhang and F.V. Bright": "Probing Solvation Processes in Supercritical Fluids with Picosecond Fluorescence Spectroscopy" presented: 1992 ACS Analytical Summer Symposium, Logan, UT (June '92).

16) F.V. Bright ${ }^{*}$, T.A. Betts, J.Zagrobelny, J. Zhang, and J.K. Rice: "Probing Solvation Dynamics in Supercritical Fluids by Picosecond Laser Spectroscopy" presented: $19^{\text {th }}$ FACSS Conference, Philadelphia, PA (Sept. '92).

17) F.V.Bright", T.A. Betts, J. Zagrobelny, J. Zhang, J.R. Rice and W.R. Peifer: "Probing Solvation Processes in Supercritical Fluids with Picosecond Time-Resolved Fluorescence Spectroscopy" to be presented: DOE Workshop on Advanced Laser Technology for Chemical Measurements, Santa Fe, NM (Oct. '92).

18) E.V. Bright ${ }^{*}$ : "Probing Solvation Dynamics in Supercritical Fluids by Picosecond Laser Spectroscopy" to be presented: Oak Ridge National Laboratory, Oak Ridge, TN (Feb. '93). 
19) F.V.Bright : "Investigation of Solvatinn Processes in Supercritical Solvents by TimeResolved Fluorescence Spectroscopy" to be presented: York, UK, XXVIII Colloquium Spectroscopicum Internationale (June '93).

\section{DOCTORAL DEGREES AWARDED}

1) Dr. Kevin S. Litwiler (12/'87 - 8/'91)

B.S., 1987, Clarion University

Ph.D., SUNY-Buffalo, August 1991

Thesis Title: Development and Use of Frequency-Domain Fluorescence Instrumentation for the Study of Surface-Immobilized Species.

First Post-Ph.D. Employment: DuPont, Environmental Studies Section-Agricultural Products Division, Research Chemist.

2) Dr. Jingfan Huang (9/'88 - 8/'91)

B.S., 1985, Fudan University (China)

Ph.D., SUNY-Bufralo, August 1991

Thesis Title: Applications of Multifrequency Phase and Modulation Fluorescence Spectroscopy to the Investigations of Microheterogeneity of Organized Media.

First Post-Ph.D. Employment: American Cyanamid, Fermentation Development Department-Medical Research Division, Research Bioanalytical Chemist.

3) Dr. Gino C. Catena (6/'87 - 10/'91)

B.S., 1986, SUNY-Buffalo

Ph.D., SUNY-Buffalo, October 1991

Thesis Title: Investigation of Cyclodextrin Inclusion Complexes by Static and Dynamic Fluorescence Spectroscopy.

First Post-Ph.D. Employment: Merck and Co., Merck Chemical Manufacturing Division, Quality Control Department, Senior Research Analyst.

4) Professor Thomas A. Betts (12/'87 - 8/'92)

B.S., 1987, Clarion University

Ph.D., SUNY-Buffalo, June 1992

Thesis Title: Investigations of Supercritical Fluid Solvation Using Fluorescence Spectroscopy.

First Post-Ph.D. Employment: Assistant Professor of Chemistry (tenure track), Kutztown State University.

5) Dr. JoAnn Zagrobelny (9/'88 - 9/'92)

B.S., 1987, SUNY-Buffalo

Ph.D., SUNY-Buffalo, July 1992

Thesis Title: Determining Intermolecular Interactions in Pure and Entrainer-Modified Supercritical Fluids Via Steady-State and Time-Resolved Fluorescence Spectroscopy. 
First Post-Ph.D. Employment: Merck Sharp \& Dohm Research Laboratories, Drug Metabolism Department, Bioanalytical Chemist.

6) Dr. Jing Zhang (1/'89 - 9/'92)

B.S., M.S., 1985, 1987, Dalian Railway Institute (China)

Ph.D., SUNY-Buffalo, August 1992

Thesis Title: Steady-State and Time-Resolved Fluorescence Studies of Reverse Micelles in Liquids and Supt, critical Solvents.

First Post-Ph.D. Employment: Pacific Northwest Laboratory (Battelle Memorial Institute), Postdoctoral Fellow with Dr. R.D. Smith. 

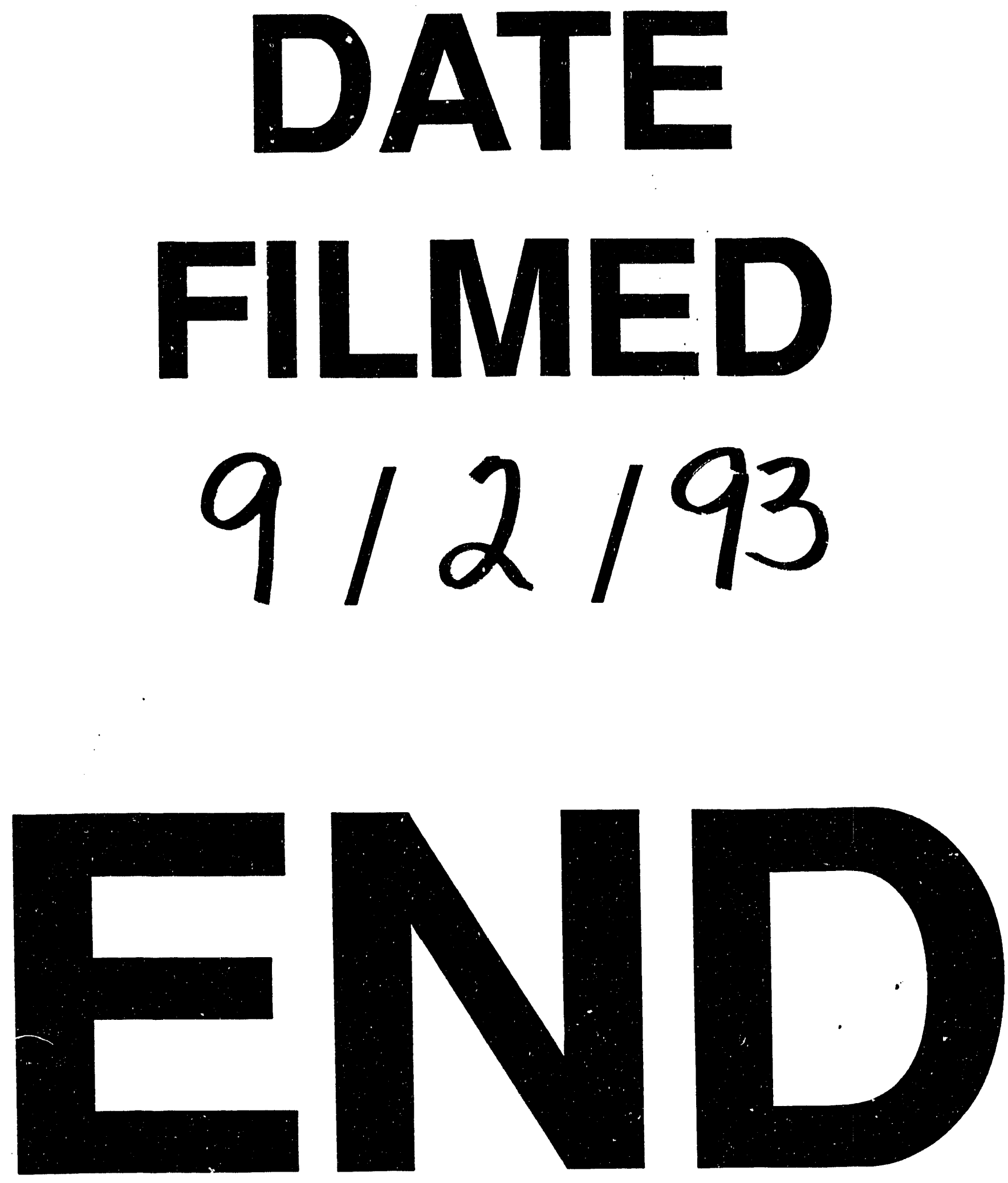
